\title{
Transmisión de Trichoconiella padwickii a coleóptilos de arroz
}

\author{
Alfonso Lovato Echeverría ${ }^{1}$, Marcelo Aníbal Carmona² \& Susana Alejandra Gutiérrez ${ }^{1}$ \\ ${ }^{1}$ Catedra de Fitopatología, Facultad de Ciencias Agrarias, Universidad Nacional del Nordeste, Sargento Cabral 2131 (3400), \\ Corrientes, Argentina; ${ }^{2}$ Fitopatología, Facultad de Agronomía, Universidad de Buenos Aires, Av. San Martín 4453 (1419), \\ Ciudad de Buenos Aires, Argentina
}

Autor para correspondencia: Alfonso Lovato Echeverría, e-mail: alfodamian@gmail.com

\section{RESUMEN}

El hongo Trichoconiella padwickii es uno de los principales patógenos de la semilla de arroz en la provincia de Corrientes, Argentina. Con el objetivo de cuantificar la eficiencia de transmisión (ET) desde la semilla a coleóptilos de arroz se realizó un ensayo “in vivo", utilizando semillas de las variedades BRS Taim, Puitá Inta-CL e Irga 424. Las semillas se sembraron en bandejas plásticas conteniendo arena estéril como sustrato e incubadas en laboratorio en condiciones de $25 \pm 2{ }^{\circ} \mathrm{C}$ y fotoperiodo de $12 \mathrm{~h}$. La ET se evaluó a los siete días, sobre 400 coleóptilos sembrados en medio agar poroto 3\%. El patógeno presentó los siguientes valores de ET: 7\% para la variedad BRS Taim; 28,5\% en Puitá Inta-CL y 8,1\% en la variedad Irga 424. Se demostró la importancia de la semilla como fuente de inóculo de T. padwickii.

Palabras-claves: Oryza sativa, fuente de inóculo, semillas.

\begin{abstract}
Transmission of Trichoconiella padwickii to rice coleoptiles

The fungus Trichoconiella padwickii is one of the main pathogens of rice seed in the province of Corrientes, Argentina. With the objective of quantifying the transmission efficiency (TE) from rice seed to coleoptiles, a trial was conducted "in vivo" using seeds of the varieties BRS Taim, Puitá Inta-CL and Irga 424. Seeds were sown in plastic trays containing sterile sand as substrate and incubated in laboratory conditions at $25 \pm 2{ }^{\circ} \mathrm{C}$ and photoperiod of $12 \mathrm{~h}$. The TE was evaluated after seven days using 400 coleoptiles put on agarbean medium $3 \%$. The TE was $7 \%, 28.5 \%$ and $8.1 \%$ for varieties BRS Taim, Puitá Inta-CL and Irga 424, respectively, demonstrating the importance of seeds as an inoculum source of T. padwickii.
\end{abstract}

Key words: Oryza sativa, inoculum source, seeds.

El cultivo de arroz (Oryza sativa L.) en Argentina es realizado en la región litoral del país, siendo la provincia de Corrientes la principal productora con un total de 95.471 ha cosechadas durante la campaña 2011-2012 (ACPA, 2012). La sanidad de la semilla de arroz es un factor muy importante, ya que la misma puede ser portadora de microorganismos patógenos y saprofitos, y además ser fuente de inóculo primario y un eficiente medio de introducción de patógenos a nuevas áreas (Mew \& Misra, 1994; Mew \& Gonzalez, 2002). Durante las campañas agrícolas 2008-2011, en análisis sanitarios de rutina de semillas procedentes de cultivos de arroz de la región, se observó que el hongo Trichoconiella padwickii (Ganguly) B. L. Jain presentó valores de incidencia en semillas desde $4 \%$ hasta 74,25\% (Gutiérrez et al., 2010b; Lovato et al., 2011). Actualmente es uno de los principales patógenos asociado al manchado del grano de arroz y es además el causante de la alternariosis, en cultivos de la provincia de Corrientes (Gutiérrez et al., 2010a).

La importancia de T. padwickii como patógeno de semilla ya fue demostrada por varios autores (Costa, 1991;
Farias et al., 2007; Islam et al., 2012; Islam et al., 2000; Mathur et al., 1972). Este hongo afecta principalmente a los granos de la panoja de arroz, lo que incide en la calidad y también en la germinación al sembrar las semillas infectadas (Ou, 1985; Mathur et al., 1972; Mew \& Misra, 1994; Mew \& Gonzales, 2002). Según Reis et al. (1999), es importante diferenciar el transporte de un patógeno por medio de la semilla de un lugar a otro y su transmisión hacia la progenie del hospedante. La simple presencia de un patógeno en la semilla no asegura su pasaje hacia la plántula, por lo que la eficiencia del pasaje, es decir la transmisión del patógeno, debe ser demostrada y cuantificada. Considerando la importancia que representa T. padwickii como patógeno de la semilla de arroz, se realizó este trabajo a fin de cuantificar su eficiencia de transmisión hacia los órganos aéreos de plántulas de arroz.

El ensayo fue conducido en el laboratorio de Fitopatología de la Facultad de Ciencias Agrarias, UNNE, Corrientes (Argentina). Se utilizaron semillas de arroz de las variedades BRS Taim, Puitá Inta-CL y Irga 424, procedentes del departamento Mercedes (Corrientes, Argentina) con 
niveles de incidencia de T. padwickii de $16 \%, 34,5 \%$ y $55,7 \%$, respectivamente. Mil doscientas semillas de arroz se sembraron en 24 bandejas plásticas con arena estéril (ocho bandejas por variedad con 50 semillas/bandeja), las que se incubaron durante siete días en condiciones de $25 \pm 2^{\circ} \mathrm{C}$ y fotoperiodo de $12 \mathrm{~h}$; posteriormente los coleóptilos de las plántulas crecidas en este sustrato se desinfectaron en una solución de hipoclorito de sodio al $1,5 \%$ por 10 min y lavados tres veces con agua estéril, durante $5 \mathrm{~min}$ cada uno (modificado de Mathur \& Kongsdal, 2003). Luego los coleóptilos se sembraron en cajas de Petri con medio agar poroto (AP) $3 \%, \mathrm{pH} 6$, con el agregado de un antibiótico (sulfato de estreptomicina). Las cajas sembradas se mantuvieron en condiciones idénticas que las descriptas anteriormente. La eficiencia de transmisión (ET) se determinó aplicando la fórmula $\mathrm{T} / \mathrm{S} * 100$, donde $\mathrm{T}$ corresponde a la incidencia en los coleóptilos colonizados por T. padwickii y $\mathrm{S}$, incidencia del patógeno en las semillas (Reis et al., 1999; Carmona et al., 2008).

Los resultados obtenidos demuestran que la transmisión del patógeno desde la semilla hacia los coleóptilos ocurrió en las tres variedades de arroz analizadas. Los coleóptilos de las plántulas de siete días de edad no presentaron síntomas y/o signos del patógeno al momento de la siembra. Posteriormente, luego de la siembra en AP sobre los mismos se desarrollaron el micelio y los esclerocios negros y globosos, correspondientes a T. padwickii (Figura 1). Si bien la variedad Irga 424 presentó una alta incidencia del patógeno en las semillas de $\operatorname{arroz}(55 \%)$ con respecto a las otras variedades, la ET del patógeno fue tan sólo de $8 \%$, en tanto en la variedad BRS Taim con $16 \%$ de incidencia en semillas, el valor de ET fue de 7\%, mientras que en Puitá-Inta CL (34,5\% de

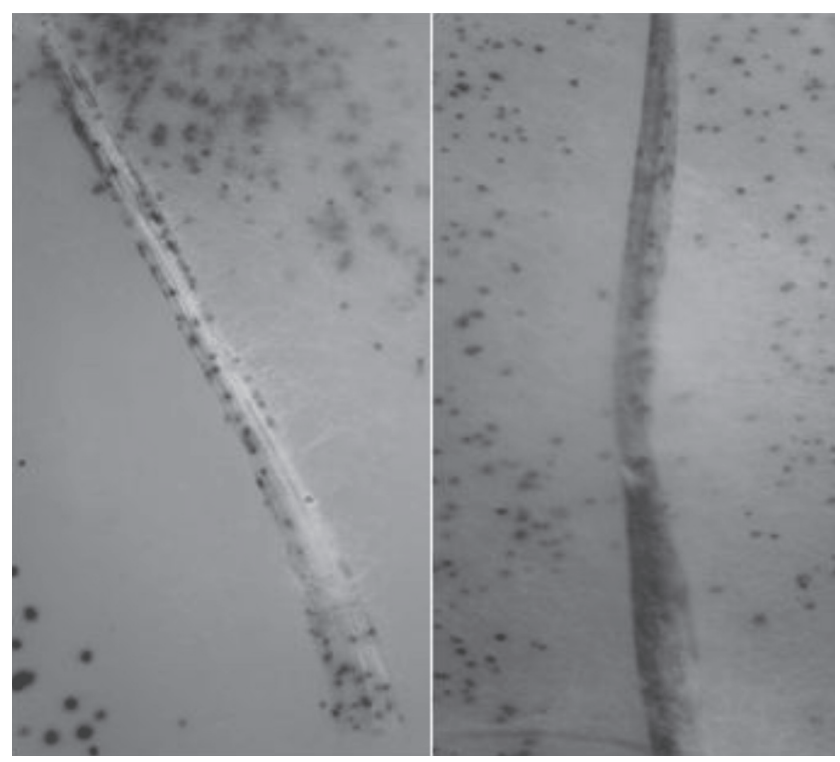

FIGURA 1 - Coleóptilos de arroz sembrados en agar poroto con desarrollo de micelio y esclerocios de Trichoconiella padwickii. incidencia), la ET fue de 28,5\% (Tabla 1). Los resultados obtenidos coinciden con los registrados por Gutiérrez (2010), quiénes observaron una ET de 18\% en coleóptilos de siete días de edad en la variedad Fortuna.

Estos resultados indican que no siempre variedades con alta incidencia del patógeno en las semillas presentarán mayor eficiencia en la transmisión hacia las plántulas, lo que reforzaría la teoría de que el transporte del hongo por las semillas no asegura necesariamente su transmisión a la progenie. Según Menten \& Bueno (1987) es bastante común que el transporte del hongo asociado a la semilla sea superior o igual a la tasa de transmisión.

Al respecto, Agarwal \& Sinclair (1997), Neergaard (1979) y Singh \& Mathur (2004) afirman que el proceso de transmisión de patógenos es influenciado por diversos factores, entre los cuales se mencionan la especie cultivada (resistencia varietal), condiciones ambientales (temperatura, luz, lluvia, humedad ambiental), tipo, humedad y microflora de suelo, $\mathrm{pH}$, población de plantas, profundidad de siembra, fertilización, supervivencia del inóculo, vigor de la semilla, y localización del inóculo. La ubicación del patógeno en la semilla es considerado como uno de los más importantes en los estudios de transmisión (Singh \& Mathur, 2004).

Con respecto a la localización de T. padwickii en semillas, Lovato et al. (2011) cuantificaron la incidencia del patógeno en todos los componentes de semillas de arroz de la variedad Irga 424 (lema, pálea, lemas estériles, pericarpio y endospermo). Dichos autores observaron que el patógeno se localiza en todas las partes de la semilla, registrando la mayor incidencia del mismo, en el endospermo y pericarpio. Estos resultados fueron semejantes a los obtenidos por Amaral et al. (1985), quiénes observaron que el pericarpio contenía mayor presencia del hongo, y Costa (1991), quién demostró que entre 5 y $30 \%$ del inóculo presente en el grano de arroz se localiza en el endospermo.

$\mathrm{La}$ presente investigación demuestra que $T$. padwickii es un hongo que se transmite de manera eficiente y asintomática, desde semillas infectadas a coleóptilos de arroz de siete días de edad. Estos resultados confirman la importancia que tiene la semilla como fuente de inóculo primario de T. padwickii y constituyen una nuevo aporte al conocimiento que existe en los países de Argentina y Brasil.

TABLA1 - Incidencia y eficiencia de transmisión de Trichoconiella padwickii desde semillas a coleóptilos de tres variedades de arroz

\begin{tabular}{lcc}
\hline \hline Variedad & $\begin{array}{c}\text { Incidencia en } \\
\text { semillas (\%) }\end{array}$ & $\begin{array}{c}\text { Eficiencia de } \\
\text { transmisión (\%) }\end{array}$ \\
\hline BRS Taim & 16,0 & 7,0 \\
Puitá Inta-CL & 34,5 & 28,5 \\
Irga 424 & 55,7 & 8,1 \\
\hline
\end{tabular}




\section{REFERENCIAS BIBLIOGRAFICAS}

ACPA (2012) Asociación Correntina de Plantadores de Arroz. Disponible en: http://www.acpaarrozcorrientes.org.ar/Noticias_ generales.html. Acceso en 13 de junio de 2012.

Agarwal VK, Sinclair JB (1997) Principles of Seed Pathology. 3rd Ed. Boca Raton FL, EEUU. CRC Press.

Amaral HM, Furlan SH, Menten JOM (1985) Localização de Dreschlera oryzae, Rhynchosporium oryzae e Trichoconiella padwickii em sementes de arroz (Oryza sativa L.). In: Congresso Brasileiro de Sementes, Resumos... Brasília DF, Brasil. Abrates. p. 118.

Carmona M, Barreto D, Moschini R, Reis EM (2008) Epidemiology and control of seed-borne Drechslera teres on barley. Cereal Research Communications 36:637-645.

Costa JDL (1991) Alternaria padwickii e Curvularia lunata: patogenicidade e transmissão por sementes de arroz irrigado. Fitopatologia Brasileira 16:15-18.

Farias CRJ, Afonso APS, Brancão CRP (2007) Ocorrência de Alternaria padwickii (Ganguly) em sementes de arroz (Oryza sativa L.) (Poacea) produzidas em quatro regiões orizícolas do Rio Grande do Sul e seu efeito sobre plântulas. Arquivos do Instituto Biológico 74:245-249.

Gutiérrez SA (2010) Monitoreo de enfermedades en semillas de arroz. Detección, cuantificación y transmisión de Alternaria padwickii y Microdochium oryzae. Tesis Doctoral, Facultad de Ciencias Agrarias, Universidad Nacional del Nordeste. Corrientes Argentina.

Gutiérrez SA, Cúndom MA, Cabrera MA, Lovato, AD (2010) Enfermedades foliares del cultivo del arroz. In: XVII Reunión de Comunicaciones Científicas y Técnicas, Resumen... Corrientes Argentina. SGCYT, UNNE. Disponible en http://www.unne.edu. ar/unnevieja/investigacion/com2010/CA-Web/wCA 005_005. pdf. Acceso en 7 de mayo de 2012.

Gutiérrez SA, Reis EM, Carmona MA (2010b) Methods for detection of Alternaria padwickii in rice seed. Journal of
Phytopathology 158:523-526.

Islam MS, Vahan QSA, Bunnarith K, Viangkum S, Merca SD (2000) Evaluation of seed health of some rice varieties under different conditions. Botanical Bulletin of Academia Sinica 41:293-297.

Islam MS, Rahman H, Pervez Z, Mahmund MR, Alam A (2012) Studies on seed borne in rice cultivars grown in non saline tidal zones of Patuakhali and their effect on seed germination. Bangladesh Research Publication Journal 6:286-290.

Lovato AD, Gutiérrez SA, Carmona MA (2011) Ubicación de Alternaria padwickii en semillas de arroz. In: II Congreso Argentino de Fitopatología, Resumen... Mar del Plata Argentina. AAF. p. 259.

Mathur SB, Kongsdal O (2003) Common Laboratory Seed Health Testing Methods for Detecting Fungi. $3^{\mathrm{a}}$ Ed. Copenhagen Dinamarca. ISTA.

Mathur SB, Mallya JI, Neergaard P (1972) Seed-borne infection of Trichoconis padwickii in rice, distribution and damage to seeds and seedlings. Proceedings of the International Seed Testing Association 37:803-810.

Mew TW, Gonzales P (2002) A Handbook of Rice Seedborne Fungi. Los Baños Filipinas. IRRI.

Mew TW, Misra JK (1994) A Manual of Rice Seed Health Testing. Manila Filipinas. IRRI.

Menten JOM, Bueno JT (1987) Transmissão de doenças pelas sementes. In: Soave J, Wetzel MMVS (Eds.) Patología de sementes. Campinas SP, Brasil. Fundaçao Cargill.

Neergaard P (1979) Seed Pathology. Vol 1. London UK. MacMillan Press Ltd.

Ou SH (1985) Rice Diseases. Kew UK. Commonwealth Mycological Institute.

Reis EM, Barreto D, Carmona M (1999) (Eds.) Patología de Semillas de Cereales de Invierno. Buenos Aires Argentina. Gráfica Condal SRL.

Singh D, Mathur SB (2004) Histopathology of Seed-Borne Infections. Boca Raton FL, EEUU. CRC Press. 